\title{
Two Brain Sites for Cannabinoid Reward
}

\author{
Abraham Zangen, ${ }^{1,2 \star}$ Marcello Solinas, ${ }^{1 \star}$ Satoshi Ikemoto, ${ }^{1}$ Steven R. Goldberg, ${ }^{1}$ and Roy A. Wise ${ }^{1}$ \\ ${ }^{1}$ National Institute on Drug Abuse, National Institutes of Health, Department of Health and Human Services, Baltimore, Maryland 21224, and ${ }^{2}$ Department \\ of Neurobiology, Weizmann Institute of Science, Rehovot 76100, Israel
}

The recent findings that ${ }^{\Delta 9}$ tetrahydrocannabinol $\left({ }^{\Delta 9} \mathrm{THC}\right)$, the active agent in marijuana and hashish, (1) is self-administered intravenously, (2) potentiates the rewarding effects of electrical brain stimulation, and (3) can establish conditioned place preferences in laboratory animals, suggest that these drugs activate biologically primitive brain reward mechanisms. Here, we identify two chemical trigger zones for stimulant and rewarding actions of ${ }^{\Delta 9} \mathrm{THC}$. Microinjections of ${ }^{\Delta 9} \mathrm{THC}$ into the posterior ventral tegmental area (VTA) or into the shell of the nucleus accumbens (NAS) increased locomotion, and rats learned to lever-press for injections of ${ }^{\Delta 9} \mathrm{THC}$ into each of these regions. Substitution of vehicle for drug or treatment with a cannabinoid $\mathrm{CB}_{1}$ receptor antagonist caused response cessation. Microinjections of ${ }^{\Delta 9}$ THC into the posterior VTA and into the posterior shell of NAS established conditioned place preferences. Injections into the core of the NAS, the anterior VTA, or dorsal to the VTA were ineffective. These findings link the sites of rewarding action of ${ }^{\Delta 9} \mathrm{THC}$ to brain regions where such drugs as amphetamines, cocaine, heroin, and nicotine are also thought to have their sites of rewarding action.

Key words: THC; reward; locomotion; ventral tegmental area; nucleus accumbens; self-administration

\section{Introduction}

Intracranial microinjections have been used to localize mechanisms of action of several psychoactive drugs, such as the sites in the brainstem where morphine triggers its analgesic actions or the sites around the third ventricle where angiotensin induces drinking. This approach has been used to determine that amphetamine (Hoebel et al., 1983), morphine (Olds, 1982), and phencyclidine (Carlezon and Wise, 1996), have rewarding actions in nucleus accumbens (NAS; where the majority of the fibers of the mesolimbic dopamine system terminate) and that nicotine (Laviolette and van der Kooy, 2003) and $\mu$ - and $\delta$-opioids (Bozarth and Wise, 1981; Olds, 1982; Devine and Wise, 1994; Zangen et al., 2002) have rewarding actions in the ventral tegmental area (VTA; the origin of the mesolimbic dopamine system). These agents are thought to be habit-forming because they activate the mesolimbic dopamine system or because they act on GABAergic neurons that receive input from or send output to the dopamine system (Wise, 1998).

${ }^{\Delta 9}$ Tetrahydrocannabinol ( ${ }^{\Delta 9} \mathrm{THC}$ ) is self-administered intravenously (Tanda et al., 2000; Justinova et al., 2003), can establish conditioned place preferences (Valjent and Maldonado 2000), can potentiate brain stimulation reward (Gardner et al., 1988), and activates the mesolimbic dopamine system ( $\mathrm{Ng}$ Cheong Ton et al., 1988; French, 1997; Tanda et al., 1997). Although demon-

\footnotetext{
Received March 9, 2004; revised March 26, 2006; accepted March 27, 2006.

A.Z. is an incumbent of the Joseph and Celia Reskin career development chair.

${ }^{*}$ A.Z. and M.S. contributed equally to this work.

Correspondence should be addressed to Roy A. Wise, National Institute on Drug Abuse, National Institutes of Health, Department of Health and Human Services, 5500 Nathan Shock Drive, Baltimore, MD 21224. E-mail: rwise@intra.nida.nih.gov.

M. Solinas' present address: Laboratoire de Biologie et Physiologie Cellulaires, Centre National de la Recherche Scientifique-6187, University of Poitiers, 40 Avenue du Recteur Pineau, 86022 Poitiers, France.

DOI:10.1523/JNEUROSCI.3554-05.2006

Copyright $\odot 2006$ Society for Neuroscience $\quad 0270-6474 / 06 / 264901-07 \$ 15.00 / 0$
}

strations of rewarding effects of ${ }^{\Delta 9} \mathrm{THC}$ appear to be very much dependent on the experimental conditions (Parolaro et al., 2005), the brain sites at which ${ }^{\Delta 9} \mathrm{THC}$ can trigger these actions are not known.

In the present study, we used microinjections into subregions of the VTA and nucleus accumbens to determine whether ${ }^{\Delta 9} \mathrm{THC}$ has rewarding or psychomotor stimulant actions in either region. Most drugs of abuse cause psychomotor activation and do so when microinjected at the same brain sites where they have rewarding actions (Wise and Bozarth, 1987). Thus, we initially screened for drug-induced locomotor activity. Next, we examined the rewarding effect of ${ }^{{ }^{9}}{ }^{\mathrm{TH}} \mathrm{HC}$ in specific portions of the VTA and nucleus accumbens using intracranial self-administration. Addictive drugs not only establish compulsive selfadministration habits, they also establish conditioned preferences for the portions of the environment in which the drug has been experienced. Therefore, we also used a conditioned placepreference paradigm to confirm rewarding effects of ${ }^{\Delta 9} \mathrm{THC}$ microinjections into subregions of the nucleus accumbens and the VTA.

\section{Materials and Methods}

Animals. Two hundred eight male Sprague Dawley rats (Charles River Laboratories, Raleigh, NC), weighing between 270 and $330 \mathrm{~g}$ at the time of surgery, were used for these experiments. They were housed in pairs before surgery and individually after surgery, and maintained under a reversed $12 \mathrm{~h}$ light/dark cycle and tested in darkness during their dark phase. Laboratory rat chow and water were continuously available in their home cages. Animals used in this study were maintained in facilities accredited by the American Association for the Accreditation of Laboratory Animal Care and the experiments were conducted in accordance with the National Institutes of Health guidelines for the care and use of laboratory animals.

Surgical procedures. Each rat was implanted unilaterally, under pentobarbital/chloral hydrate anesthesia (31 and $142 \mathrm{mg} / \mathrm{kg}$, respectively), with a 26-gauge guide cannula above the posterior VTA (pVTA), anterior VTA (aVTA), or nucleus accumbens shell or core. The cannulas were 
angled toward the midline at $6^{\circ}$ (VTA) to avoid penetration of the midsagittal sinus or at $16^{\circ}$ (nucleus accumbens) to avoid penetration of the lateral ventricle. Stereotaxic coordinates (flat skull) were $5.0 \mathrm{~mm}$ posterior $(\mathrm{P})$ to bregma, $1.6 \mathrm{~mm}$ lateral $(\mathrm{L})$ to the midline, and $7.8 \mathrm{~mm}$ ventral (V) to the skull surface (measured along the trajectory of the angled cannula) for anterior VTA placements; $6.1 \mathrm{P}, 1.3 \mathrm{~L}$, and $7.8 \mathrm{~V}$ for posterior VTA placements; $6.1 \mathrm{P}, 1.3 \mathrm{~L}$, and $6.8 \mathrm{~V}$ for the region dorsal to the posterior VTA; $5.8 \mathrm{P}, 2.3 \mathrm{~L}$, and $8.0 \mathrm{~V}$ for the substantia nigra $(\mathrm{SNr}) ; 1.5$ anterior (A), $3.8 \mathrm{~L}$, and $6.2 \mathrm{~V}$ for the accumbens core placement; and 1.8 $\mathrm{A}, 3.2 \mathrm{~L}$, and $6.6 \mathrm{~V}$ for the primary (midlevel) nucleus accumbens shell placement. In the last experiment, additional groups were tested with anterior (2.2 A) or posterior (1.2 A) placements in the accumbens shell. Each rat was implanted with a guide cannula in a single brain site and separate groups of rats were prepared for the locomotor activity experiments (total, $n=67$ ), the intracranial self-administration experiments (total, $n=91$ ), and the conditioned place preference experiments (total, $n=50$ ). For intracranial injections, an injection cannula that protruded $1 \mathrm{~mm}$ below the guide cannula was used.

Drugs. ${ }^{\Delta 9} \mathrm{THC}(200 \mathrm{mg} / \mathrm{ml}$ of ethanol) was obtained from the National Institute on Drug Abuse (Rockville, MD). The ethanol was evaporated under nitrogen and the ${ }^{\Delta 9} \mathrm{THC}$ then dissolved in artificial CSF (aCSF) supplemented with $35 \%$ (w/v) 2-hydroxypropyl-1- $\beta$-cyclodextrin (Sigma-RBI, St. Louis, MO). The aCSF consisted of the following (in $\mathrm{mm}$ ): $125 \mathrm{NaCl}, 2.5 \mathrm{KCl}, 0.5 \mathrm{NaH}_{2} \mathrm{PO}_{4}, 5.0 \mathrm{Na}_{2} \mathrm{HPO}_{4}, 1.0 \mathrm{MgCl}_{2}$, and 1.2 $\mathrm{CaCl}, \mathrm{pH}$ 7.4. The maximal concentration of ${ }^{\Delta 9} \mathrm{THC}$ was $7.3 \mathrm{~mm}$. The concentration of ${ }^{\Delta 9} \mathrm{THC}$ in our vehicle was analyzed weekly using gas chromatography (Giroud et al., 2001). After 6 weeks at room temperature, the concentration of ${ }^{\Delta 9} \mathrm{THC}$ decreased by $12 \%$. Although the rate of degradation was relatively low, we cannot rule out the possibility that some derivates could decrease the psychoactive properties of ${ }^{\Delta 9} \mathrm{THC}$. Therefore, we prepared fresh ${ }^{\Delta 9} \mathrm{THC}$ solutions for each set of experiments. Moreover, the order of doses in the locomotion experiments was counterbalanced and we did not notice an effect of the given order of doses on the experimental outcome.

The cannabinoid $\mathrm{CB}_{1}$ receptor $\left(\mathrm{CB}_{1} \mathrm{R}\right)$ antagonist, rimonabant (SR$141716 \mathrm{~A}$ ) was obtained from the National Institute on Drug Abuse and suspended in a solution 1:1:18 of Tween 80 , ethanol, and saline and administered intraperitoneally in a volume of $2 \mathrm{ml} / \mathrm{kg}$.

Locomotion. Locomotion was estimated from beam crossings in a $40 \times$ $40 \mathrm{~cm}$ open field (AccuScan Instruments, Columbus, OH). After $5 \mathrm{~d}$ of recovery from surgery, the rats were habituated to the test apparatus in six daily $1 \mathrm{~h}$ sessions. On subsequent test days, each rat received an intracranial microinjection of ${ }^{\Delta 9} \mathrm{THC}(0,100,300,1000$, or $3000 \mathrm{pmol}$ in aCSF, supplemented with 2-hydroxypropyl1- $\beta$-cyclodextrin) or vehicle (aCSF, $0.5 \mu \mathrm{l}$ ) delivered through polyethylene tubing over $60 \mathrm{~s}$. The injector was left in place for $30 \mathrm{~s}$ after injection and then the rat was placed in the test apparatus. Each rat was tested for 60 min daily but was given drug injections only every other day; this was to minimize the development of conditioned locomotion. The order of doses was counterbalanced.

Intracranial self-administration. After $5 \mathrm{~d}$ of recovery from surgery, each rat was placed in an operant chamber equipped with two levers and cue lights $1 \mathrm{~cm}$ above each lever. Lever-presses on one lever ("active" lever) activated a head-mounted injection pump (Ikemoto and Sharpe, 2001), causing an intracranial injection, and illuminated the cue light above that lever for $10 \mathrm{~s}$. Additional lever presses during this $10 \mathrm{~s}$ period were counted but did not cause further injections. Responses on the other lever ("inactive" lever) were counted but caused no injections and illuminated no cue light. Each rat was trained for five sessions; sessions were separated by $72 \mathrm{~h}$. Such intervals were chosen to avoid possible dysphoric effects that may occur $24 \mathrm{~h}$ after administration of ${ }^{\Delta 9} \mathrm{THC}$ (Lepore et al., 1995). Sessions lasted $3 \mathrm{~h}$. In sessions 1 through 3, the rats of each group received an $8 \mathrm{~s}, 100 \mathrm{nl}$ injection of 66 or $200 \mathrm{pmol}$ of ${ }^{\Delta 9} \mathrm{THC}$ or vehicle for each lever press. Two doses of ${ }^{\Delta 9} \mathrm{THC}$ were used in the accumbens shell because the results of the locomotor activity tests indicated that this area was more sensitive than the VTA to the drug. In session 4, each rat earned only vehicle. In session 5, rats that received ${ }^{\Delta 9} \mathrm{THC}$ in sessions $1-3$ were exposed again to the same doses of ${ }^{\Delta 9} \mathrm{THC}$.

To confirm that the rewarding effects of intracranial ${ }^{\Delta 9} \mathrm{THC}$ were receptor-mediated and not some physicochemical reaction to the injec- tion (Wise and Hoffman, 1992), one group of rats with cannula placements in the posterior VTA and one group with cannula placements in the shell of nucleus accumbens were trained as described but were pretreated with the cannabinoid antagonist rimonabant (SR-141716A, 1 $\mathrm{mg} / \mathrm{kg}$, i.p.) $60 \mathrm{~min}$ before the fourth session. This dose and timing produces maximal blockade of ${ }^{\Delta 9}$ THC's effects (Solinas et al., 2003). These animals were pretreated with the antagonist vehicle $(0.3 \%$ Tween 80 in saline) on the third and fifth days of testing.

Conditioned place preference. The conditioned place preference (CPP) test was performed in a three-compartment apparatus (MED Associates, St. Albans, VT) consisting of a narrow middle compartment connecting two large side compartments. The two side compartments differed by floor type, by wall color, and by intensity of illumination. The walls of one side chamber were black and the walls of the other side chamber were white. The illumination of the two side chambers was adjusted to balance the side preferences; the chamber with black walls was more brightly illuminated than the chamber with white walls. The illumination was adjusted until it produced equal side preference in an independent group of rats. No preconditioning tests were conducted to increase the sensitivity of the tests (Bardo et al., 1995). In the conditioning phase, the animal experienced the effects of intracranial ${ }^{\Delta 9} \mathrm{THC}$ in one of the two side compartments for $60 \mathrm{~min}$ on each of $3 \mathrm{~d}$, and experienced the effects of vehicle injections in the other side compartment for $60 \mathrm{~min}$ on the intervening days. While in these compartments, rats received infusions of either ${ }^{\Delta 9} \mathrm{THC}$ ( $200 \mathrm{pmol}$ ) or vehicle every $6 \mathrm{~min}$, via the microinjection system used in the self-administration experiments. The frequency of injection was selected on the basis of the self-administration experiments in the attempt to mimic the self-administered ${ }^{\Delta 9} \mathrm{THC}$ doses. The exposure to conditioning compartments was counterbalanced. One day after the last conditioning session, the animal was tested for conditioned place preference; it was placed in the middle compartment with the barriers removed and the times spent in each compartment were recorded over a 15 min period.

Histology. After each experiment, the animals were killed by $\mathrm{CO}_{2}$ inhalation. Evans blue $(0.5 \mu \mathrm{l})$ was injected through the injection cannulas and the brains were removed and soaked in $4 \%$ paraformaldehyde. Thirty-micrometer frozen coronal sections were cut and examined for the tip of the injection cannula. Exclusion criteria were based on Paxinos and Watson (1998). Anterior versus posterior VTA placements were determined according to the presence (posterior) or absence (anterior) of the interpeduncular nucleus just below the VTA in the coronal slice that included the tip of the injection cannula. Reconstruction of the placement of the cannulas and microphotographs are depicted in Figure 1.

Statistical analysis. Data are expressed as the mean \pm SEM of values obtained from the indicated number of rats. Locomotor or CPP data were analyzed by repeated ANOVA coupled with application of Bonferroni's post hoc test as indicated. Data from the intracranial drug selfadministration paradigm were analyzed by ANOVA with linear and quadratic trend analysis. The comparisons of interest were between days 3-5. Such comparison was performed for both the number of intracranial infusions and the preference (ratio) between the active and inactive lever presses. A significant linear trend across days 3-5 (data fit best with a straight line) confirmed that the animals did not discriminate the day 4 challenge conditions (when they earned vehicle rather than ${ }^{\Delta 9} \mathrm{THC}$ or when they were pretreated with the $\mathrm{CB}_{1}$ antagonist rimonabant) from the day 3 and day 5 normal reward conditions. A significant quadratic trend (data best fit with a "U"-shaped function) confirmed significant response decrement in the challenge condition on day 4 and significant recovery on the normal testing condition on day 5 .

\section{Results}

\section{Effect of intracranial ${ }^{\Delta 9} \mathrm{THC}$ on locomotor activity}

Microinjection of ${ }^{\Delta 9} \mathrm{THC}$ into the pVTA induced up to $60 \%$ increases in locomotor activity $\left(F_{(4,40)}=2.84 ; p=0.036\right)$ (Fig. $2 A$ ) within the first $5 \mathrm{~min}$ after the injection and remained hyperactive for over $30 \mathrm{~min}$ (Fig. $2 \mathrm{C}$ ). The effect of ${ }^{\Delta 9} \mathrm{THC}$ microinjection into the pVTA was dose-dependent (Fig. 2A). The total 

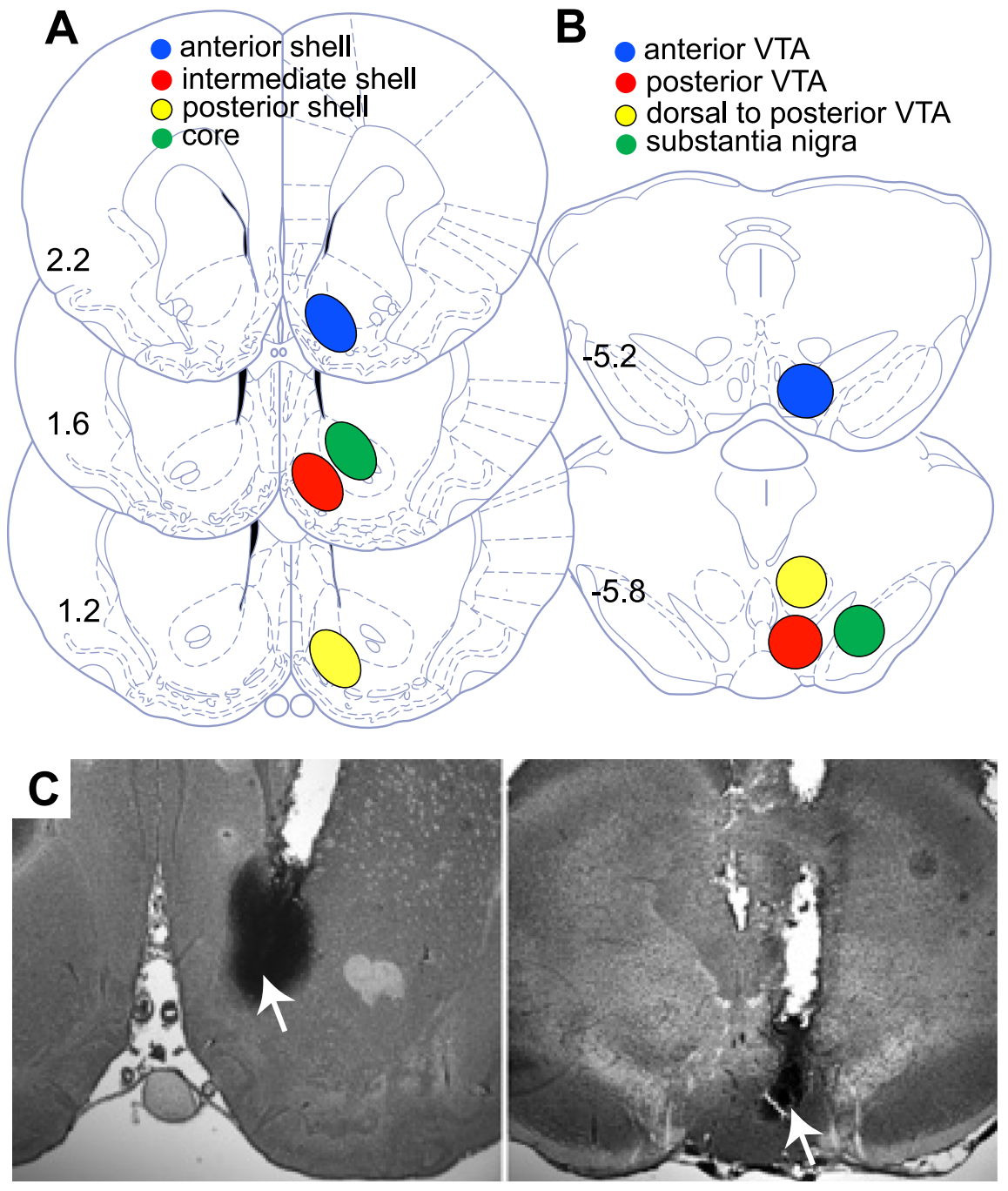

Figure 1. Injection site location in the nucleus accumbens $(\boldsymbol{A})$ and the VTA $(\boldsymbol{B})$. Drawings are adapted from the rat atlas of Paxinos and Watson (1998). Numbers on each plate represent distance from bregma. $\boldsymbol{C}$, Microphotographs of injection sites in the nucleus accumbens shell (left) and posterior VTA (right). The arrows indicate the tips of the injection cannula.

ing days was $20.4 \pm 2.1,13.6 \pm 0.7,10.8 \pm$ 0.8 and $9.9 \pm 1.4$ for the pVTA, aVTA, dpVTA, and pVTA-vehicle groups, respectively. With posterior VTA injections, the animals learned to press the active lever regularly (Fig. 3B) and prefer it over the inactive lever (Fig. 3C) within the first training session. Responding was significantly depressed on day 4, when vehicle was substituted for drug, and recovered on day 5 , when drug reward was reinstated (Fig. 3A). This was reflected in both the intake data $\left(F_{(1)}=8.20 ; p=0.0125\right)$ and the preference data $\left(F_{(1)}=21.82 ; p=\right.$ 0.0004 ) for animals receiving ${ }^{\Delta 9} \mathrm{THC}$ in the posterior VTA and in both the intake data $\left(F_{(1)}=11.27 ; p=0.0057\right)$ and the preference data $\left(F_{(1)}=14.38 ; p=0.0026\right)$ for animals receiving ${ }^{\Delta 9} \mathrm{THC}$ in the anterior VTA. In each case, the data were best fit by a quadratic trend (U function) that reflected depression on day 4 and recovery on day 5. Responding in the dorsal and vehicle control groups was linear across the $3 \mathrm{~d}$; neither vehicle substitution nor reinstatement of reward altered the behavior of the dorsal control group.

Rats also learned to self-administer ${ }^{\Delta 9} \mathrm{THC}$ injections into the shell region of the nucleus accumbens (Fig. $4 A$ ). Rats receiving either dose of ${ }^{\Delta 9} \mathrm{THC}$ in the shell region responded more over the first three training days than did rats receiving vehicle $\left(F_{(2,18)}=3.58 ; p=0.049\right)$. The average number of responses/session during the first three training days was $15.9 \pm 0.7$, $12.9 \pm 0.9,10.1 \pm 0.2,9.5 \pm 0.7$ and $7.4 \pm$ 0.9 for the shell (200 pmol/infusion), shell (66 pmol/infusion), core (200 pmol/infusion), core-vehicle, and shell-vehicle groups, respectively. With shell injections,

distance traveled was $2074 \pm 276 \mathrm{~cm}$ after vehicle and $3286 \pm 480$ $\mathrm{cm}$ after $1 \mathrm{nmol}$ of THC microinjection into the posterior VTA.

However, microinjection of ${ }^{\Delta 9} \mathrm{THC}$ into the aVTA or a region just dorsal to the posterior VTA (dpVTA) failed to significantly affect locomotion (Fig. $2 A$ ). ${ }^{\Delta 9}$ THC also induced modest locomotor activation (up to $40 \%$ above baseline) when injected into the shell $\left(F_{(4,60)}=3.42 ; p=0.013\right)$, but not the core, of nucleus accumbens (Fig. $2 B, D$ ). The effect of ${ }^{\Delta 9} \mathrm{THC}$ microinjection into the nucleus accumbens shell was dose-dependent (Fig. $2 B$ ). The total distance traveled was $1811 \pm 217 \mathrm{~cm}$ after vehicle and $2601 \pm 271 \mathrm{~cm}$ after $0.3 \mathrm{nmol}$ of THC microinjection into the accumbens shell.

\section{Self-administration of ${ }^{\Delta 9} \mathrm{THC}$ into the VTA, nucleus accumbens, and substantia nigra}

Rats learned to lever-press for ${ }^{\Delta 9} \mathrm{THC}$ injections into the posterior VTA (Fig. 3A-C). During the first $3 \mathrm{~d}$ of training, rats receiving ${ }^{\Delta 9} \mathrm{THC}$ into the posterior VTA responded significantly more than rats that earned vehicle injections $\left(F_{(1,12)}=5.22 ; p=0.041\right)$. Rats receiving ${ }^{\Delta 9} \mathrm{THC}$ into the anterior VTA or into a site just dorsal to the VTA did not respond significantly (Fig. 3A). The average number of responses/session during the first three train- responding was sustained and regular throughout sessions when ${ }^{\Delta 9}$ THC was available (Fig. $4 \mathrm{~B}$ ). Responding extinguished on the fourth day, when vehicle was substituted for drug, and was reinstated on the fifth day, when drug was again made available (Fig. $4 A)$. This was reflected in the intake but not the preference data for days 3-5 in animals receiving $200 \mathrm{pmol} /$ infusion $\left(F_{(1)}=\right.$ $18.37 ; p=0.0004)$ and in animals receiving $66 \mathrm{pmol} /$ infusion $\left(F_{(1)}=42.08 ; p=0.0001\right)$. There were no significant differences across days $3-5$ for animals receiving ${ }^{{ }^{9}} \mathrm{THC}$ in the core of nucleus accumbens or for animals receiving vehicle in either area. Discrimination between the active and inactive levers was not sufficiently robust for statistical reliability; there were no significant differences in preference and no groups by days interaction across days 3-5 (Fig. 4C).

When other groups of animals self-administering ${ }^{\Delta 9} \mathrm{THC}$ into the VTA (Fig. $3 D, E$ ) or the shell of nucleus accumbens (Fig. $4 D, E$ ) were challenged with the $\mathrm{CB}_{1}$ antagonist rimonabant 60 min before a ${ }^{\Delta 9}$ THC self-administration session on day 4 , responding decreased; when ${ }^{\Delta 9} \mathrm{THC}$ alone was given on day 5 , responding recovered. This was reflected in the intake but not the preference data for days 3-5 in animals lever-pressing for ${ }^{\Delta 9} \mathrm{THC}$ 

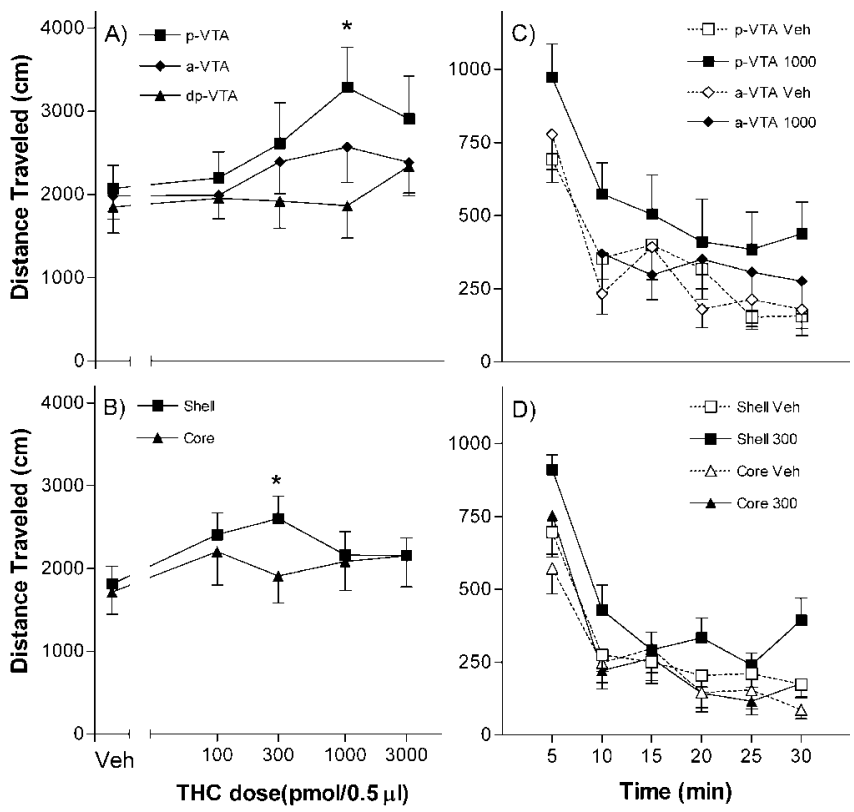

Figure 2. Distance traveled in response to ${ }^{\Delta 9} \mathrm{THC}$ or vehicle infusions into various brain regions. The effects of various doses injected into the pVTA $(n=11)$, aVTA $(n=13)$, or dpVTA $(n=8)(\boldsymbol{A})$, or into the shell $(n=16)$ or core $(n=13)$ of nucleus accumbens $(\boldsymbol{B})$ are presented. $C, D$, Time course of the ${ }^{\Delta 9}$ THC or vehicle effects on the locomotor activity. ${ }^{* *} p<0.01 ;$ post hoc comparison after significant ANOVA for repeated measures main effect; Bonferroni's post hoc test. Error bars indicate SE.

into the VTA $\left(F_{(1)}=7.91 ; p=0.0101\right)$ or into the shell of nucleus accumbens $\left(F_{(1)}=9.51 ; p=0.0064\right)$.

None of the four rats prepared with substantia nigra cannulas learned to lever-press for ${ }^{\Delta 9} \mathrm{THC}$ injections.

\section{Effect of intracranial ${ }^{\Delta 9} \mathrm{THC}$ injections on conditioned place preference}

Rats developed significant preferences for the compartment where they experienced posterior but not anterior VTA injections of ${ }^{\Delta 9}$ THC (Fig. 5). No significant preferences for the drugassociated compartment were observed in rats that had been given their injections into the middle of the accumbens shell. Because recent reports suggest differential involvement of the anterior and posterior portions of the shell of nucleus accumbens in motivation (Martin et al., 2002; Reynolds and Berridge, 2002), additional groups were tested with more anterior or more posterior placements in accumbens shell. Modest conditioned place preferences were established in the animals given their injections in the posterior but not the anterior shell of nucleus accumbens (Fig. 5). Statistical analysis revealed a significant treatment/site interaction $\left(F_{(4,45)}=3.667 ; p=0.001\right)$ and the Bonferroni's post hoc test indicated a significant effect of treatment in the posterior VTA and the posterior nucleus accumbens sites.

\section{Discussion}

The present study identifies two brain trigger zones for rewarding effects of ${ }^{\Delta 9}$ THC: one in the VTA and one in the nucleus accumbens shell. The effective sites of action appear to be reasonably well localized to the posterior VTA and the posterior portion of the accumbens shell, as injections in nearby regions were either ineffective or markedly less effective in each paradigm. Drug reward was evident in both the intracranial drug selfadministration paradigm and in the conditioned placepreference paradigm.

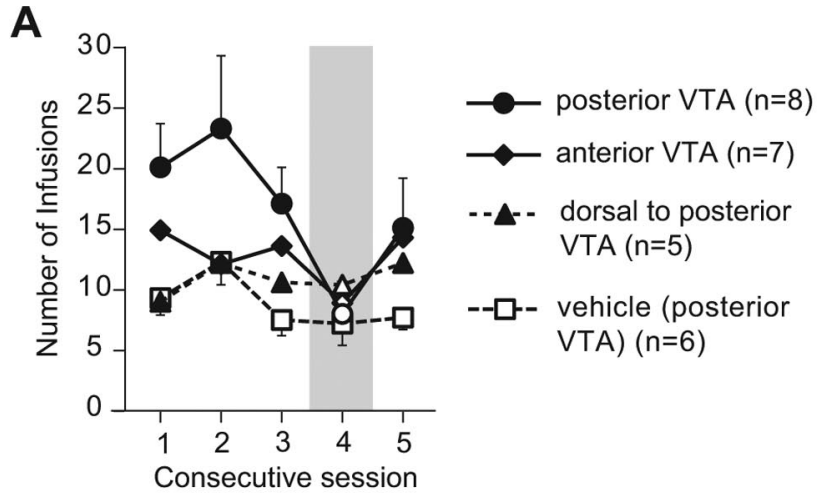

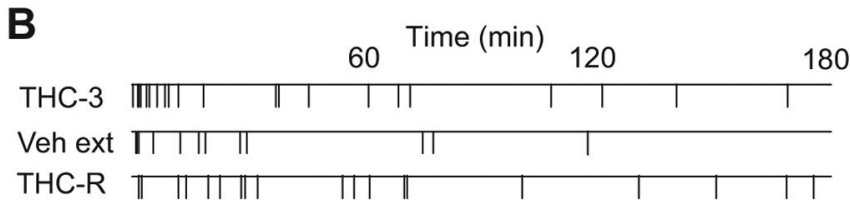
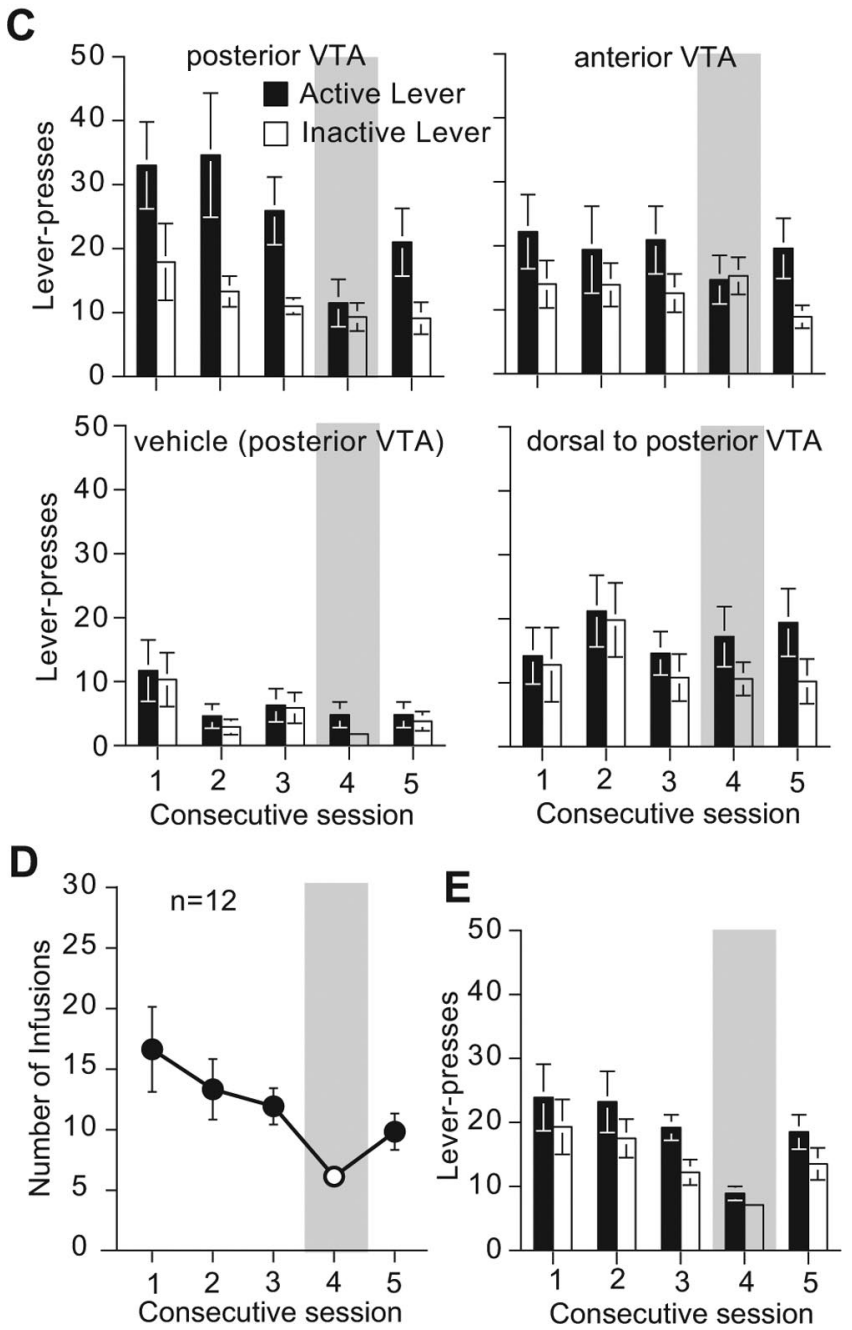

Figure 3. Intra-VTA self-administration of $200 \mathrm{pmol}$ infusions of ${ }^{\Delta 9} \mathrm{THC}$ or vehicle (VEH) as a function of injection site and test session. $\boldsymbol{A}$, Number of earned infusions. $\boldsymbol{B}$, Temporal pattern of responding for a representative animal receiving ${ }^{49} \mathrm{THC}$ in the pVTA on days $3-5$. C, The responses on the "active" and "inactive" levers. $\boldsymbol{D}, \boldsymbol{E}$, Effect of the CB1 antagonist, rimonabant, or its vehicle on self-administration of ${ }^{\Delta 9} \mathrm{THC}$ into the posterior VTA as measured by number of earned infusions (D) and "active"/"inactive" lever responses (E). Error bars indicate SE. 


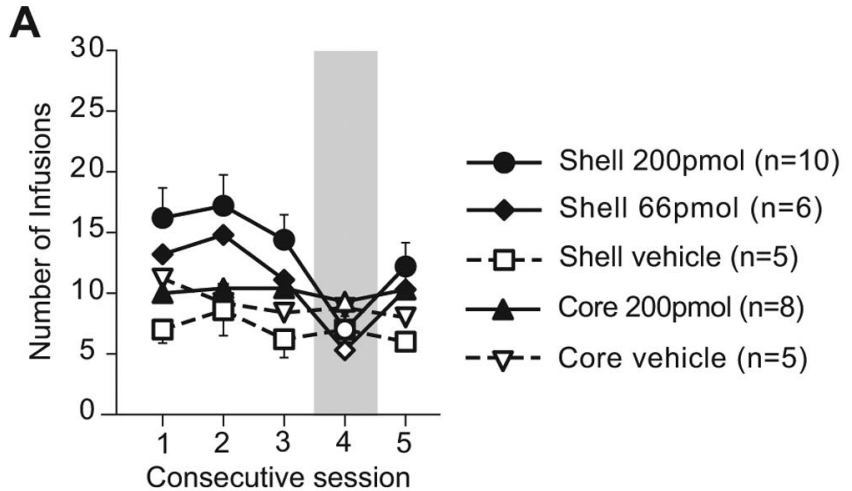

B

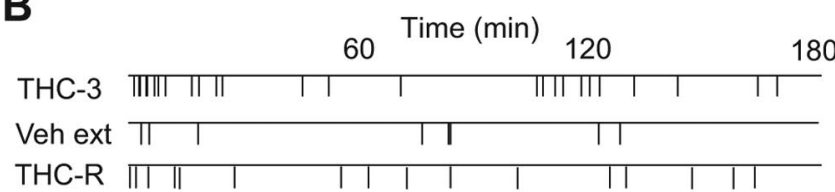

C
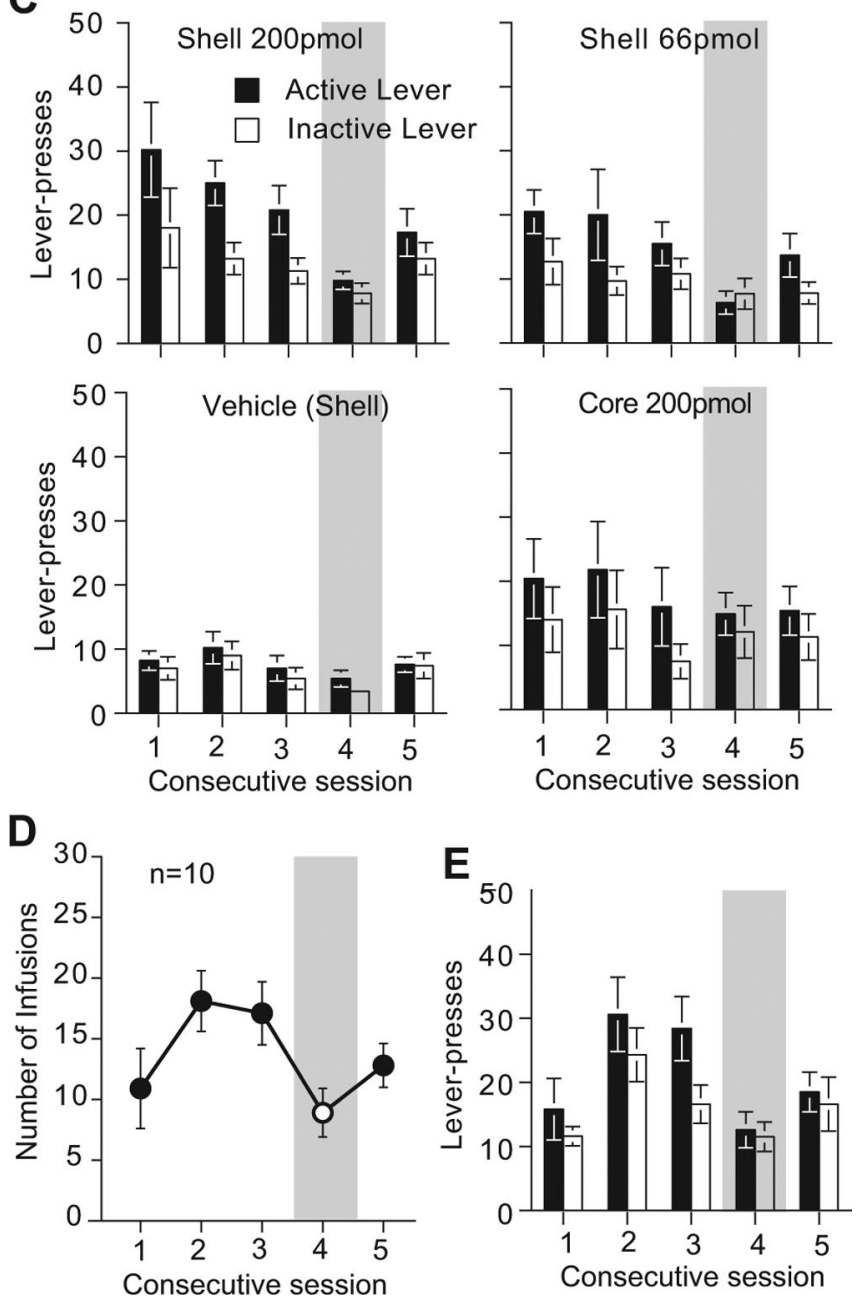

Figure 4. Intra-accumbens self-administration of ${ }^{\Delta 9} \mathrm{THC}$ or vehicle (VEH) as a function of injection site and test session. $\boldsymbol{A}$, Number of earned infusions. $\boldsymbol{B}$, Temporal pattern of responding for a representative animal receiving $200 \mathrm{pmol}{ }^{\Delta 9} \mathrm{THC}$ in the shell on days $3-5$. $\boldsymbol{C}$, The responses on the "active" and "inactive" levers. $\boldsymbol{D}, \boldsymbol{E}$, The effect of the CB1 antagonist, rimonabant, or its vehicle on self-administration of ${ }^{\triangle 9} \mathrm{THC}$ into the accumbens shell as measured by number of earned infusions $(\boldsymbol{D})$ and "active"/"inactive" lever responses $(\boldsymbol{E})$. Error bars indicate SE.

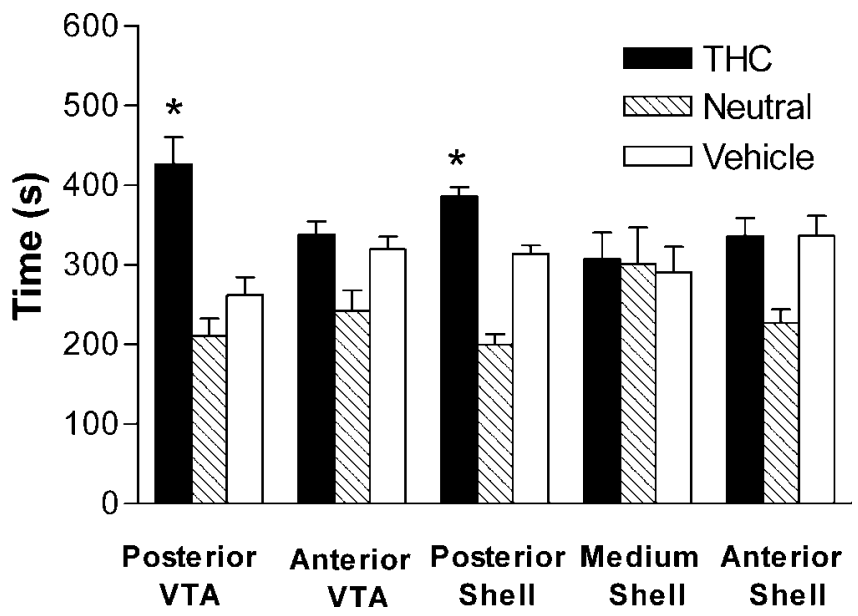

Figure 5. Conditioned place preference induced by intracranial ${ }^{\Delta 9} \mathrm{THC}$ as a function of injection site. After three pairings of 60 min daily conditioning sessions, rats were exposed to a 15 min test session. Data are presented as means \pm SEM values of the total time spent in the ${ }^{\Delta 9} \mathrm{THC}$-associated and the vehicle-associated compartments during the test session. ${ }^{*} p<$ 0.02 ; Bonferroni's post hoc test.

The finding that ${ }^{\Delta 9} \mathrm{THC}$ was self-administered into the posterior VTA and dependent on $\mathrm{CB}_{1} \mathrm{R}$ activation (Fig. $3 D$ ) is somewhat surprising given the low levels of $\mathrm{CB}_{1} \mathrm{R}$ (Herkenham et al., 1991 ) in that region. Indeed, $C_{1} R$ mRNA is expressed in GABAergic striatonigral and striatopallidal neurons (Hohmann and Herkenham, 2000), only a small fraction of which project to the VTA. Indeed, $\mathrm{CB}_{1} \mathrm{R}$ mRNA is expressed preferentially in the dorsal and lateral portions of the striatum, the least likely portion of the striatum to project to VTA. This explains why there is dense $\mathrm{CB}_{1} \mathrm{R}$ binding in the zona reticulata of the $\mathrm{SNr}$ and only very weak $\mathrm{CB}_{1} \mathrm{R}$ binding in the VTA. Nevertheless, recent data suggest that CB1 receptors are present and modulate neurotransmission in the VTA (for review, see Lupica et al., 2004). In addition, because animals with injection cannulas directed to the $\mathrm{SNr}$ did not learn to lever press for ${ }^{\Delta 9} \mathrm{THC}$ injection at this site, we conclude that diffusion to the $\mathrm{SNr}$ does not explain the rewarding effects of ${ }^{\Delta 9}$ THC in the posterior VTA. It is important to note that, although electrical stimulation of zona compacta of the substantia nigra $\left(\mathrm{SNc}\right.$ ) is rewarding, neither the $\mathrm{SNr}$, where $\mathrm{CB}_{1} \mathrm{R}$ binding is strong, or the $\mathrm{SNc}$, where $\mathrm{CB}_{1} \mathrm{R}$ binding is similar to that seen in VTA, has been reported as a site of rewarding drug injections.

Several findings suggest that the anterior and posterior VTA play differential roles in reward function. Microinjections of GABA agonists and GABA antagonists can each be rewarding (Ikemoto et al., 1997a, 1998; Laviolette and van der Kooy, 2001), depending on whether they are given in the anterior or posterior portions of the structure (Ikemoto et al., 1997a, 1998), and depending on which of the GABAergic outputs of the region are activated (Laviolette and van der Kooy, 2001). In addition, the opiate $\mu$-receptor agonist endomorphin-1 (Zangen et al., 2002), the cholinergic receptor agonist carbachol (Ikemoto and Wise, 2002), ethanol (Rodd-Henricks et al., 2000), or acetaldehyde (Rodd et al., 2004) are self-administered into the posterior VTA, but not the anterior VTA. Finally, overexpression of the AMPA receptor subunit GluR1 or of phospholipase $\mathrm{C} \gamma 1$ (a protein involved in neurotrophic signaling) in the anterior VTA potentiates systemic morphine reinforcement, whereas overexpression in the posterior VTA makes morphine aversive (Carlezon et al., 2000; Bolanos et al., 2003). The present results with THC add to the findings suggesting functional differentiation between these two portions of the VTA. 
That injections into the shell of the nucleus accumbens were effective, whereas injections into the core were not, fits with the fact that systemic ${ }^{\Delta 9} \mathrm{THC}$ releases dopamine in the shell but not the core of accumbens (Tanda et al., 1997) and is consistent with the findings that nomifensine, cocaine, a mixture of dopamine $\mathrm{D}_{1}$ and $\mathrm{D}_{2}$ agonists (Ikemoto et al., 1997b), and phencyclidine are self-administered into the shell much more readily than into the core (Carlezon and Wise, 1996; Ikemoto et al., 1997a; Ikemoto 2003). It is surprising, however, that conditioned place preferences were not established with injections into the same midlevel portion of the shell where the drug was self-administered. Because reward function is greatly decreased if the reward is delayed from the time of the instrumental response (Black et al., 1985), the intracranial drug self-administration paradigm is expected to be more sensitive to placement accuracy than the conditioned place-preference paradigm. In place-preference conditioning, immediacy is less important and more time is available for a drug to diffuse to its target from an off-target injection site. Nonetheless, ${ }^{\Delta 9}$ THC failed to establish conditioned place preferences when injected into the midshell site where the drug was selfadministered. A modest place preference, weaker than that established with posterior VTA injections, was established with posterior accumbens shell injections. This is consistent with the impression that VTA self-administration of the drug was more robust than accumbens self-administration.

That posterior shell injections caused place preferences, whereas anterior or midlevel shell injections did not, fits well with recent findings (Martin et al., 2002) that the posterior accumbens is more involved than the anterior accumbens in the reinforcing effects of intravenous heroin. It does not fit obviously with the suggestions of Reynolds and Berridge (2002) that the anterior shell is important for positive and the posterior shell for negative motivation. Their suggestion was based on their finding that microinjections of the GABA agonist muscimol into the anterior shell induced feeding and conditioned place preference, whereas muscimol injections into the posterior shell induced defensive behaviors and conditioned place avoidance. Thus, it appears that the anterior and posterior shell have different motivational functions, but it remains to be determined how accumbens cells are differently affected by muscimol and ${ }^{\Delta 9} \mathrm{THC}$ in each region and how these effects interact with motivational circuitry. Because cannabinoids inhibit GABAergic synaptic transmission in the nucleus accumbens (Manzoni and Bockaert, 2001), it is possible that the overall effect of local activation of $\mathrm{CB}_{1}$ receptors would be opposite from that produced by a GABAergic agonist.

The present data confirm that cannabinoids have reinforcing effects in the same brain regions implicated in opiate [posterior VTA (Zangen et al., 2002)] and stimulant [NAS (Hoebel et al., 1983; Carlezon and Wise, 1996)] addiction, and that these effects are dependent on $\mathrm{CB}_{1} \mathrm{R}$ activation. The fact that ${ }^{\Delta 9} \mathrm{THC}$ in these brain regions can establish self-administration habits in lower animals fits well with previous observations that ${ }^{\Delta 9} \mathrm{THC}$ is selfadministered intravenously by squirrel monkeys (Tanda et al., 2000), that it potentiates the rewarding effects of direct electrical stimulation of reward pathways in rats (Gardner et al., 1988), and that it, like other drugs of abuse (Di Chiara and Imperato, 1988), activates mesolimbic dopamine neurons (French, 1997) causing release of dopamine in nucleus accumbens ( $\mathrm{Ng}$ Cheong Ton et al., 1988; Tanda et al., 1997).

The present demonstration that ${ }^{\Delta 9} \mathrm{THC}$ injections into the ventral tegmental area and shell of nucleus accumbens are sufficient for reward in rodents does not mean that either of these sites of action is necessary for the rewarding effects of systemically administered cannabis in humans. There are potential species differences in responsiveness to the rewarding action ${ }^{\Delta 9} \mathrm{THC}$, and smoked cannabis delivers the active ingredient to brain sites not reached by our intracranial injections. It is possible, although it does not seem likely on present knowledge, that smoked cannabis activates reward sites in other structures and that it does not reach concentrations in the brain sufficient to activate one or both of the sites we studied here. That caveat notwithstanding, the present data suggest that the habit-forming effects of cannabis share more with such addictive drugs as cocaine and heroin than with drugs such as hallucinogens that have their known actions in different substrates and are not self-administered by lower animals.

\section{References}

Bardo MT, Rowlett JK, Harris MJ (1995) Conditioned place preference using opiate and stimulant drugs: a meta-analysis. Neurosci Biobehav Rev 19:39-51.

Bolanos CA, Perrotti LI, Edwards S, Eisch AJ, Barrot M, Olson VG, Russell DS, Neve RL, Nestler EJ (2003) Phospholipase C $\gamma$ in distinct regions of the ventral tegmental area differentially modulates mood-related behaviors. J Neurosci 23:7569-7576.

Bozarth MA, Wise RA (1981) Intracranial self-administration of morphine into the ventral tegmental area in rats. Life Sci 28:551-555.

Carlezon Jr WA, Wise RA (1996) Rewarding actions of phencyclidine and related drugs in nucleus accumbens shell and frontal cortex. J Neurosci 16:3112-3122.

Carlezon Jr WA, Haile CN, Coppersmith R, Hayashi Y, Malinow R, Neve RL, Nestler EJ (2000) Distinct sites of opiate reward and aversion within the midbrain identified using a herpes simplex virus vector expressing GluR1. J Neurosci 20:RC62.

Devine DP, Wise RA (1994) Self-administration of morphine, DAMGO, and DPDPE into the ventral tegmental area of rats. J Neurosci 14:1978-1984.

Di Chiara G, Imperato A (1988) Drugs abused by humans preferentially increase synaptic dopamine concentrations in the mesolimbic system of freely moving rats. Proc Natl Acad Sci USA 85:5274-5278.

French ED (1997) ${ }^{\Delta 9}$-Tetrahydrocannabinol excites rat VTA dopamine neurons through activation of cannabinoid CB1 but not opioid receptors. Neurosci Lett 226:159-162.

Gardner EL, Paredes W, Smith D, Donner A, Milling C, Cohen D, Morrison D (1988) Facilitation of brain stimulation reward by delta 9-tetrahydrocannabinol. Psychopharmacology (Berl) 96:142-144.

Giroud C, Menetrey A, Augsburger M, Buclin T, Sanchez-Mazas P, Mangin P (2001) Delta(9)-THC, 11-OH-Delta(9)-THC and Delta(9)-THCCOOH plasma or serum to whole blood concentrations distribution ratios in blood samples taken from living and dead people. Forensic Sci Int 123:159-164.

Herkenham M, Lynn AB, Johnson MR, Melvin LS, de Costa BR, Rice KC (1991) Characterization and localization of cannabinoid receptors in rat brain: a quantitative in vitro autoradiographic study. J Neurosci 11:563-583.

Hoebel BG, Monaco AP, Hernandez L, Aulisi EF, Stanley BG, Lenard L (1983) Self-injection of amphetamine directly into the brain. Psychopharmacology (Berl) 81:158-163.

Hohmann AG, Herkenham M (2000) Localization of cannabinoid CB(1) receptor mRNA in neuronal subpopulations of rat striatum: a doublelabel in situ hybridization study. Synapse 37:71-80.

Ikemoto S (2003) Involvement of the olfactory tubercle in cocaine reward: intracranial self-administration studies. J Neurosci 23:9305-9511.

Ikemoto S, Sharpe LG (2001) A head-attachable device for injecting nanoliter volumes of drug solutions into brain sites of freely moving rats. J Neurosci Methods 110:135-140.

Ikemoto S, Wise RA (2002) Rewarding effects of carbachol and neostigmine in the posterior ventral tegmental area. J Neurosci 22:9895-9904.

Ikemoto S, Murphy JM, McBride WJ (1997a) Self-infusion of GABA(A) antagonists directly into the ventral tegmental area and adjacent regions. Behav Neurosci 111:369-380.

Ikemoto S, Glazier BS, Murphy JM, McBride WJ (1997b) Role of $D_{1}$ and $D_{2}$ receptors in the nucleus accumbens in mediating reward. J Neurosci 17:8580-8587. 
Ikemoto S, Murphy JM, McBride WJ (1998) Regional differences within the rat ventral tegmental area for muscimol self-infusions. Pharmacol Biochem Behav 61:87-92.

Justinova Z, Tanda G, Redhi GH, Goldberg SR (2003) Self-administration of ${ }^{\Delta 9}$-tetrahydrocannabinol (THC) by drug naive squirrel monkeys. Psychopharmacology 169:135-140.

Laviolette SR, van der Kooy D (2001) GABA(A) receptors in the ventral tegmental area control bidirectional reward signalling between dopaminergic and non-dopaminergic neural motivational systems. Eur J Neurosci 13:1009-1015.

Laviolette SR, van der Kooy D (2003) Blockade of mesolimbic dopamine transmission dramatically increases sensitivity to the rewarding effects of nicotine in the ventral tegmental area. Mol Psychiatry 8:50-59.

Lepore M, Vorel SR, Lowinson J, Gardner EL (1995) Conditioned place preference induced by delta 9-tetrahydrocannabinol: comparison with cocaine, morphine, and food reward. Life Sci 56:2073-2080.

Lupica CR, Riegel AC, Hoffman AF (2004) Marijuana and cannabinoid regulation of brain reward circuits. Br J Pharmacol 143(2):227-234.

Manzoni OJ, Bockaert J (2001) Cannabinoids inhibit GABAergic synaptic transmission in mice nucleus accumbens. Eur J Pharmacol 412:R3-R5.

Martin TJ, Kim SA, Lyupina Y, Smith JE (2002) Differential involvement of mu-opioid receptors in the rostral versus caudal nucleus accumbens in the reinforcing effects of heroin in rats: evidence from focal injections of beta-funaltrexamine. Psychopharmacology (Berl) 161:152-159.

Ng Cheong Ton JM, Gerhardt GA, Friedemann M, Etgen AM, Rose GM, Sharpless NS, Gardner EL (1988) The effects of delta 9tetrahydrocannabinol on potassium-evoked release of dopamine in the rat caudate nucleus: an in vivo electrochemical and in vivo microdialysis study. Brain Res 451:59-68.

Olds ME (1982) Reinforcing effects of morphine in the nucleus accumbens. Brain Res 237:429-440.

Parolaro D, Vigano D, Rubino T (2005) Endocannabinoids and drug dependence. Curr Drug Targets CNS Neurol Disord 4:643-655.

Paxinos G, Watson, CS (1998) The rat brain in stereotaxic coordinates. San Diego: Academic.

Reynolds SM, Berridge KC (2002) Positive and negative motivation in nu- cleus accumbens shell: bivalent rostrocaudal gradients for GABA-elicited eating, taste "liking”/“disliking” reactions, place preference/avoidance, and fear. J Neurosci 22:7308-7320.

Rodd-Henricks ZA, McKinzie DL, Crile RS, Murphy JM, McBride WJ (2000) Regional heterogeneity for the intracranial self-administration of ethanol within the ventral tegmental area of female Wistar rats. Psychopharmacology (Berl) 149:217-224.

Rodd ZA, Melendez RI, Bell RL, Kuc KA, Zhang Y, Murphy JM, McBride WJ (2004) Intracranial self-administration of ethanol within the ventral tegmental area of male Wistar rats: evidence for involvement of dopamine neurons. J Neurosci 24:1050-1057.

Solinas M, Panlilio LV, Antoniou K, Pappas LA, Goldberg SR (2003) The cannabinoid CB1 antagonist SR-141716A differentially alters the reinforcing effects of heroin under continuous-reinforcement, fixed-ratio and progressive-ratio schedules of drug self-administration in rats. J Pharmacol Exp Ther 306:93-102.

Tanda G, Pontieri FE, Di Chiara G (1997) Cannabinoid and heroin activation of mesolimbic dopamine transmission by a common $\mu_{1}$ opioid receptor mechanism. Science 27:2048-2050.

Tanda G, Munzar P, Goldberg SR (2000) Self-administration behavior is maintained by the psychoactive ingredient of marijuana in squirrel monkeys. Nat Neurosci 3:1073-1074.

Valjent E, Maldonado R (2000) A behavioural model to reveal place preference to delta 9-tetrahydrocannabinol in mice. Psychopharmacology (Berl) 147:436-438.

Wise RA (1998) Drug-activation of brain reward pathways. Drug Alcohol Depend 51:13-22.

Wise RA, Bozarth MA (1987) A psychomotor stimulant theory of addiction. Psychol Rev 94:469-492.

Wise RA, Hoffman DC (1992) Localization of drug reward mechanisms by intracranial injections. Synapse 10:247-263.

Zangen A, Ikemoto S, Zadina JE, Wise RA (2002) Rewarding and psychomotor stimulant effects of endomorphin-1: anteroposterior differences within the ventral tegmental area and lack of effect in nucleus accumbens. J Neurosci 22:7225-7233. 